\title{
TEORIA CRÍTICA DA SOCIEDADE E O SENTIDO POLÍTICO DA EDUCAÇÃO
}

\author{
Luiz Roberto Gomes*
}

\section{Resumo}

O artigo situa na tradição intelectual da Teoria Crítica da Sociedade o sentido político da educação. Trata-se de colocar em evidência o projeto de emancipação social e as possibilidades de realização de uma experiência não conformista com relação à realidade existente. Nesse contexto, serão apresentadas duas perspectivas teóricas da acepção frankfurtiana de Teoria Crítica, e que consideram como condição para a formação de pessoas emancipadas a vinculação entre educação e política: a de Theodor Adorno, em que a educação verdadeira transcende a dimensão da adaptação ao mundo vigente, através da recolocação da experiência formativa (Bildung), como forma de crítica à condição de semiformação (Halbbildung); e a de Jürgen Habermas, em que a educação deve formar a capacidade avaliativa e argumentativa dos cidadãos, a fim de fortalecer o espaço público, e garantir a participação efetiva dos interesses da sociedade civil.

Palavras-chave: Teoria Crítica. Política. Educação.

\section{Introdução}

Em concordância com as teses principais do livro, Em Busca da Política, de Zygmunt Bauman (2000), hoje em dia, para além da promulgação de inúmeras políticas educacionais, está cada vez mais difícil convencer as pessoas sobre a relevância do sentido originário da formação política e da defesa do "bem comum". Trata-se de um contexto complexo, com dilemas culturais, políticos e econômicos desafiadores, e que exige, do ponto de vista filosófico e da teoria social, uma análise abrangente sobre o que de fato está ocorrendo na sociedade contemporânea. Para o propósito de compreensão desse fenô-

* Doutor em Educação (Filosofia e História da Educação) pela Universidade Estadual de Campinas, Brasil (2005). Professor Adjunto do Programa de Pós-Graduação em Educação e do Departamento de Educação da Universidade Federal de São Carlos - SP (luizrgomes@ufscar.br). 
meno, é oportuna a reflexão acerca dos conceitos de "pós-globalização" (FUKUYAMA; DAVIS; ALENCASTRO, 2009), "globalização" (IANNI, 2002 e SANTOS, 2005), "pós-modernidade" (LYOTARD, 2002 e VATTIMO, 2002) e "pós-nacionalismo" (HABERMAS, 2001).

É diante de um cenário de recuo do "público" e de avanço do "privado" que afronta a sociedade atual, e do reducionismo da formação à sua dimensão técnico-instrumental, que propomos, à luz da Teoria Crítica da Sociedade, uma reflexão sobre o sentido político da educação. A política, enquanto dimensão vital da sociedade, que compunha a essência cultural da Paidéia grega e do ideário moderno da Bildung, encontra-se hoje eclipsada no interior de uma concepção de sociedade em que impera, de forma reducionista, a dimensão privada, administrativa e gerencial da política. Essa forma de conceber a sociedade tem gerado o esvaziamento da "esfera pública" e o consequente distanciamento da "sociedade civil" dos temas eminentemente sociais e humanos. É nesse contexto que colocamos em questão o próprio sentido da educação, com o propósito de discutir os seus fundamentos e os rumos da educação contemporânea.

Vale ressaltar que, em outros países da América Latina, o tema da formação política tem sido debatido com bastante veemência, o que pode ser constatado no estudo recente empreendido por Carlos Cullen na Argentina e que foi publicado em 2008 sob o título "Perfiles ético-políticos de la educación".

Recorrer à Teoria Crítica da Sociedade na denominação assumida pela Escola de Frankfurt, como recurso teórico-metodológico, parece ser uma alternativa viável para o enfrentamento dessa questão, principalmente pela possibilidade de referenciar, numa tradição teórica sedimentada, a atitude crítico-educativa necessária para a realização de um projeto de emancipação social. Com tal propósito, recorreremos ao pensamento de Theodor W. Adorno e de Jürgen Habermas, como forma de subsidiar teoricamente a reflexão proposta. Ressalta-se que esses autores exerceram e continuam exercendo forte influência sobre os diversos estudos realizados por pesquisadores brasileiros, e que fazem, de alguma forma, a aproximação entre Teoria Crítica e Educação.

\section{Semiformação e educação política em Theodor Adorno}

No modelo teórico-crítico de Theodor Adorno, a educação política é identificada à educação para a emancipação. Trata-se de uma crítica à disposição educativa de se adaptar "cegamente" à condição social vigente. A análise dessa tese fundamental de Adorno remete, pois, à explicitação de alguns conceitos centrais de sua teoria, tais como: indústria cultural, Halbbildung (semiformação), Bildung (formação cultural), educação e emancipação, que 
serão abordados aqui com o propósito de subsidiar a compreensão crítica do sentido da educação política em Adorno.

Na Dialética do Esclarecimento, publicada em 1947, e que marcou a tradição intelectual da Teoria Crítica, Adorno e Horkheimer apresentam, com significativa lucidez, uma análise sobre a caracterização social objetiva da perda da dimensão emancipatória, gerada na dialética da razão. Dessa forma, tal como assinalada por Wolfgang Leo Maar, "A Dialética do Esclarecimento constitui a expressão da subjetividade ameaçada, a semiformação, e das forças anônimas que ameaçam a subjetividade, a indústria cultural" (MAAR, 1995, p. 20).

Como podemos notar, a percepção crítica de Adorno e Horkheimer, em estabelecer um diagnóstico preciso sobre o processo de regressão do esclarecimento à ideologia, mediante a "mistificação das massas" e conversão das pessoas em "objeto de dominação", ocorre num estágio de significativo progresso do Aufklärung (esclarecimento), que, para Kant (1985), significava uma condição para a emancipação. Mas como uma sociedade altamente desenvolvida em termos de esclarecimento poderia ser tutelada e dominada pela própria "cultura"? Aqui está o grande mérito da Dialética do Esclarecimento, ao submeter à crítica a condição de uma sociedade supostamente esclarecida, tal como registrado pelos próprios autores, logo no início do livro:

No sentido mais amplo do progresso do pensamento, o esclarecimento tem perseguido sempre o objetivo de livrar os homens do medo e de investi-los na posição de senhores. Mas a terra totalmente esclarecida resplandece sob o signo de uma calamidade triunfal (ADORNO; HORKHEIMER, 1985, p. 19).

Os autores constatam que a "sociedade totalmente esclarecida" não passa de uma "sociedade administrada", e nessa os indivíduos se vêem completamente anulados em face do poder econômico, da visão utilitária e da racionalidade técnico-instrumental, que impinge à sociedade a sua condição de alienação e enclausuramento.

Com o conceito de indústria cultural, Adorno e Horkheimer esclarecem que há um processo de imposição da estrutura social, tal como concebido pelo modo de produção capitalista, e que descobre na face instrumental do esclarecimento e na racionalidade técnica a forma sutil de reificar a cultura e transformá-la em cultura de massa. Ela manipula as necessidades sociais, através de um processo de "integração e assimilação voluntária" das pessoas em uma suposta "ordem" estabelecida, como se fosse única. É nisso que consiste o caráter ideológico da indústria cultural: reificar a práxis social com as formas de integração da cultura.

Na Teoria da Semicultura, Adorno enfatiza a necessidade de se construir uma teoria abrangente, que transcenda a simplificação pedagógica, e que seja 
capaz de diagnosticar a crise da formação cultural manifestada - na onipresença do espírito alienado - pela forma generalizada de conversão da Bildung (formação cultural) em Halbbildung (semiformação). Nas palavras do autor:

Apesar de toda ilustração e de toda informação que se difunde (e até mesmo com sua ajuda) a semiformação passou a ser a forma dominante da consciência atual [...] a formação nada mais é que a cultura tomada pelo lado de sua apropriação subjetiva [...] ela tem um duplo caráter: remete à sociedade e intermedeia esta e a semiformação (ADORNO, 1996, p. 389).

Para Adorno, é no processo de reprodução material da sociedade que é possível captar a dialética da "formação" e da "semiformação". Na sociedade contemporânea, a significação germânica da Bildung, especialmente na acepção da "liberdade", dos "valores" que orientavam a razão prática, foi reduzida a discursos ideológicos, desvinculados da ação social. Com isso, a promessa da emancipação e da autonomia, que era a principal razão do ideal iluminista moderno, foi solapada e substituída pela adaptação e submissão disciplinada à lógica da dominação. Assim, a dimensão crítica da cultura, que deveria garantir a emancipação, cede lugar à semiformação, em que predomina a racionalidade instrumental voltada para a adaptação e o conformismo à situação vigente.

Essa condição social de conversão da cultura em pseudocultura chega a travar a realização da autêntica experiência formativa, a ponto de Adorno dizer que: "a única possibilidade que resta à cultura é auto-reflexão crítica sobre a semiformação, em que necessariamente de converteu" (ADORNO, 1996, p. 410). Essas considerações de Adorno sobre a condição social da semicultura e a necessidade da auto-reflexão crítica sobre a semiformação são fundamentais para a compreensão do sentido político da educação, já que:

Em um mundo onde a educação é um privilégio e o aprisionamento da consciência impede de toda maneira o acesso das massas à experiência autêntica das formações espirituais, já não importam tanto os conteúdos ideológicos específicos, mas o fato de que simplesmente haja algo preenchendo o vácuo da consciência expropriada e desviando a atenção do segredo conhecido por todos (ADORNO, 1998, p. 20).

A esse respeito, os ensaios de Adorno sobre a educação, e que estão reunidos no livro Educação e Emancipação (1995) são claros quanto aos limites e possibilidades da educação no contexto semiformação. No ensaio Educação - Para $q u \hat{e}$ ?, Adorno explicita a sua concepção de educação:

[...] concebo como sendo educação [...] não a assim chamada modelagem de pessoas, porque não temos o direito de modelar pessoas a partir do seu exterior; 
mas também não a mera transmissão de conhecimentos, cuja característica de coisa morta já foi mais do que destacada, mas a produção de uma consciência verdadeira. Isto seria inclusive da maior importância política; sua idéia, se é permitido dizer assim, é uma exigência política [...] uma democracia com o dever de não apenas funcionar, mas operar conforme seu conceito, demanda pessoas emancipadas. Uma democracia efetiva só pode ser imaginada enquanto uma sociedade de quem é emancipado (ADORNO, 1995a, p. 141-142; grifos meus).

Como podemos observar, Adorno foca o sentido político da educação na produção de uma consciência verdadeira, ao se contrapor criticamente à condição social de mera adaptação e conformismo à situação vigente. É nesse contexto que a indústria cultural forma, pela ideologia da semicultura, uma consciência falsa da realidade social. Daí a necessidade da formação de uma consciência desalienada e politicamente emancipada.

Esclarecido o conceito de educação e o sentido político da educação emancipatória, Adorno nos adverte sobre a necessidade da reflexão crítica a respeito das possibilidades de emancipação, a partir do condicionamento social da própria cultura. No ensaio Crítica Cultural e Sociedade, de 1969, ele salienta que hoje a sociedade ela própria é sua ideologia, ou seja, uma forma de sociedade determinada conforme certo modelo de produção social dos homens, de modo que a apreensão do conteúdo dessa ideologia passará necessariamente pela análise crítica do condicionamento social vigente. É por isso que a emancipação não pode ser idealizada de forma ingênua; pelo contrário, ela precisa ser concebida no bojo do próprio ordenamento social. Dessa forma, Adorno destaca, textualmente, os dois problemas relacionados à emancipação:

Penso, sobretudo, em dois problemas difíceis que é preciso levar em conta quando se trata de emancipação. Em primeiro lugar, a própria organização do mundo em que vivemos e a ideologia dominante - hoje muito pouco parecida com uma determinada visão de mundo ou teoria -, ou seja, a organização do mundo converteu-se a si imediatamente em sua própria ideologia. Ela exerce uma pressão tão intensa sobre as pessoas que supera toda educação. [...] No referente ao segundo problema [...] emancipação significa o mesmo que conscientização, racionalidade (ADORNO, 1995a, p. 143).

Adorno insiste na ideia de que é necessário decifrar as condições sociais que determinam o modo de ser dos homens, por intermédio da reflexão racional - "conscientização" - das condições de produção da realidade social. Aqui reside um dos elementos fundamentais da emancipação política, a saber, a contradição que impede a conciliação total. Como diria Adorno, no ensaio 
Tempo Livre (1969): “É evidente que ainda não se alcançou inteiramente a integração da consciência [...]. Os interesses reais do indivíduo ainda são suficientemente fortes para, dentro de certos limites, resistirem à apreensão" (ADORNO, 1995b, p. 81).

Se não há a integração total da sociedade, devido à própria contradição social, que funciona como o antídoto da semiformação, então continua existindo a possibilidade de emancipação. Essa questão foi abordada por Adorno, no último ensaio do livro Educação e Emancipação: “[...] é preciso começar a ver efetivamente as enormes dificuldades que se opõem à emancipação nesta organização do mundo [...]. O motivo é a contradição social" (ADORNO, 1995a, p. 181).

Como podemos notar, a educação emancipatória não se sustenta pela retórica, e sim pela crítica das condições objetivas que promovem a semiformação, ou seja, pela identificação da contradição social que bloqueia a aptidão para a experiência formativa autônoma - Bildung, sendo esta substituída, de forma "natural" pela configuração heterônoma de formação - Halbbildung. É por essa razão fundamental que Adorno (1995a, p. 183) salienta que “a única concretização efetiva da emancipação consiste em que aquelas poucas pessoas interessadas nessa direção orientem toda sua energia para que a educação seja uma educação para a contradição e para a resistência". E isso seria plenamente possível, se conseguíssemos, por exemplo, mostrar aos alunos as ideologias presentes na vida da sociedade culturalmente construída, além do despertar da consciência quanto aos enganos a que somos submetidos, permanentemente, no interior da própria cultura. Trata-se de uma crítica inerente ao próprio condicionamento social e suas contradições. É assim que Adorno identifica, no provimento da consciência do condicionamento social, o potencial crítico da educação. Nas suas palavras:

É necessário contrapor-se a uma tal ausência de consciência, é preciso evitar que as pessoas golpeiem para os lados sem refletir a respeito de si próprias. A educação tem sentido unicamente como educação dirigida a uma auto-reflexão crítica (ADORNO, 1995a, p. 121. grifo meu).

É dessa forma, que se configura, portanto, o sentido político da educação em Adorno, promovida pela auto-reflexão crítica do condicionamento social, mediante a consciência pública das contradições que geram o enclausuramento do sujeito. Trata-se de uma educação negativa (ADORNO, 1975), que realiza a crítica à forma ideológica de prover a semicultura, desobstruindo, dessa forma, o caminho para a realização da experiência formativa e, consequentemente, da emancipação. 


\section{Educação, esfera pública e ação política em Jürgen Habermas}

A vasta produção bibliográfica de Habermas não dispõe de textos específicos sobre a educação, com exceção de algumas considerações sobre a universidade e os sistemas educativos. Todavia, a sua construção teórica é rica em elementos formativos e que podem ser relevantes para o enfrentamento dos desafios do nosso tempo. Trata-se, em especial, dos processos emancipatórios de aprendizagem que a sociedade pode desenvolver, com o restabelecimento do vínculo entre a esfera pública e a sociedade civil.

No contexto de uma sociedade amplamente administrada pela racionalidade instrumental e pela indústria cultural, conforme a crítica à razão moderna de Adorno e Horkheimer, a possibilidade de emancipação parece estar cada vez mais ameaçada e minimizada frente às formas perversas de dominação social. Mesmo considerando as dificuldades de realização da emancipação, no modelo teórico-crítico da razão monológica de seus antecessores, Habermas reconhece o mérito da crítica à razão moderna de Adorno e Horkheimer, e procura dar um passo além, ao encontrar na razão comunicativa outra perspectiva teórica, com possibilidades fecundas de subsidiar a realização do projeto moderno de emancipação.

Com o pressuposto teórico da razão comunicativa, Habermas procura deixar claro, logo no prefácio da Teoria da Ação Comunicativa, publicada em 1981, que o tema da racionalidade deve ser reconhecido como tema central da teoria social crítica, e esta precisa ser reconstruída a partir de uma concepção dual de racionalidade, em que a racionalidade instrumental e a comunicativa se colocam como complementares à produção e reprodução da vida em sociedade. É com esse pressuposto fundamental que ele explicita a abrangência de sua teoria:

A categoria de ação comunicativa [...] permite o acesso a três complexos temáticos relacionados entre si: trata-se, em primeiro lugar, de um conceito de racionalidade comunicativa [...] que é capaz de fazer frente às reduções cognitivo-instrumentais que se fazem da razão; em segundo lugar, de um conceito de sociedade articulado em dois níveis, que associa os paradigmas de mundo da vida e sistema (...); e finalmente, de uma teoria da modernidade que explica o tipo de patologias sociais que hoje se tornam cada vez mais visíveis [...] (HABERMAS, 1999a, p. 10).

O modelo teórico-crítico da ação comunicativa de Habermas implica, em termos de concepção de racionalidade, uma mudança estrutural de paradigma: da razão subjetiva, fundada nos critérios de verdade e êxito das relações do sujeito que conhece e age segundo fins, com o mundo de objetos ou 
estados de coisas possíveis, para a razão intersubjetiva, assentada nos procedimentos argumentativos da comunicação linguística, e no reconhecimento intersubjetivo das pretensões de validade de um discurso. Essa mudança de paradigma decorre, fundamentalmente, dos limites do modelo auto-reflexivo da razão moderna, a fim de evitar o risco

[...] de um pensamento centrado no sujeito, que não conseguiu manter livre a coação não coercitiva da razão tanto dos traços totalitários de uma razão instrumental [...] como também dos traços totalizantes de uma razão inclusiva que tudo anexa e que, no final, triunfa como unidade sobre todas as diferenças (HABERMAS, 2000, p. 473).

Habermas entende que racionalidade encontra a sua maior expressão na forma como os sujeitos, capazes de linguagem e de ação, fazem uso do conhecimento, e não na sua aquisição, como muitos defendem. Dessa forma, ele desenvolve um conceito de racionalidade que se projeta em duas direções distintas: a racionalidade cognitivo-instrumental e a racionalidade comunicativa. Essa diferenciação em dois tipos de racionalidade, que decorre da reflexão de Habermas sobre o processo de racionalização social, retoma o problema sociológico da passagem das sociedades tradicionais para as sociedades modernas, que fora abordado por Weber (2007) e considerado por Habermas como um dos temas centrais da teoria social. Com tal propósito, Habermas recorre a Weber para focalizar no conceito de esferas culturais de valor a chave de compreensão dos conteúdos e conceitos dos complexos fenômenos do racionalismo ocidental:

A racionalização cultural, que surge das estruturas da consciência típicas das sociedades modernas, se estende aos componentes cognitivos, aos componentes estético-expressivos e aos moral-avaliativos da tradição religiosa. Com a ciência e a técnica, a arte autônoma e os valores relativos à manifestação expressiva que o sujeito faz de si, com as idéias universalistas que subjazem o direito e a moral, se produz uma diferenciação de três esferas de valor, cada uma das quais obedecendo a sua própria lógica. Com isso, não somente se cobra coerência da 'legalidade própria, interna' dos componentes morais da cultura, como também aumenta a tensão entre estas esferas. (HABERMAS, 1999a, p. 222).

Para Habermas, o problema enfrentado pelas sociedades modernas, com a diferenciação entre as esferas culturais de valor, refere-se ao tema do conflito ou das tensões que se estabelecem, mediante os complexos de racionalidade descritos, de modo que é colocada em questão a capacidade de integração que compõe a unidade do mundo da vida. Esses conflitos, que antes eram absorvidos pela figura mítica ou pela imagem religioso-metafísica do mundo, 
que atribuíam o sentido de unidade espiritual e política a todos os membros da comunidade, através dos seus arquétipos (Deus, natureza e razão), perdem o seu sentido, na medida em que a razão se dissocia numa pluralidade de esferas de valor, destruindo, por consequência, a sua própria unidade.

A instabilidade dos mecanismos de produção e reprodução da sociedade, fruto da desarmonia dos diversos domínios da vida social, cada vez mais desconectados da visão de mundo tradicional, acaba gerando, nas sociedades modernas, um estado de conflito e de tensão, típicos das distintas esferas culturais de valor. Para Habermas (1999a), é exatamente no aspecto da segregação da razão, legitimada pela lógica dos complexos de racionalidade, que reside o grande problema da modernidade, de modo que o sentido deva ser restabelecido a partir de uma integração entre as diferentes esferas de valor. Dessa forma, o conflito e a tensão produzida pela sociedade moderna passam a ser estabilizados por meio de uma diferenciação da racionalidade das ações sociais.

O que fica claro na Teoria da Ação Comunicativa é que Habermas concebe, a partir da sua noção de racionalidade, dois tipos distintos de ação social, com características bem distintas do modelo teleológico de ação concebido por Weber. De um lado, a ação instrumental, orientada para o êxito, para o sucesso da reprodução material da sociedade, e de outro a ação comunicativa, que se orienta pelo entendimento entre os participantes de uma discussão racional, livre de impedimentos, e que permite a reprodução simbólica da sociedade. A ação do tipo comunicativo obriga-nos a pressupor as condições de realização de uma comunicação não distorcida. Esses dois tipos de ação social implicam um conceito de sociedade que considera como referência os domínios da vida social. Assim temos: o sistema, em que predominam as ações do tipo instrumental; e o mundo da vida, em que prevalecem as ações do tipo comunicativo.

Para Habermas (1999b) as categorias sistema e mundo da vida são úteis para uma compreensão mais clara do problema sociológico da passagem das sociedades tradicionais para as modernas. A unidade encontrada entre sistema e mundo da vida nas sociedades tradicionais esfacelou-se, e suas lógicas específicas ganharam autonomia uma em relação à outra. Assim, o dissenso e o conflito, presentes nas sociedades modernas, não ocorreram apenas entre as esferas culturais de valor, mas também entre a lógica sistêmica e a lógica do mundo da vida, entre a lógica instrumental e a lógica comunicativa, abrindo, inclusive, a possibilidade de "colonização" de uma sobre a outra. É nesse contexto de argumentação que se explicita a tese habermasiana da "colonização do mundo da vida pelo sistema".

Do ponto de vista de uma teoria crítica da sociedade, em que a emancipação ocupa um lugar de destaque, Habermas entende que não basta resistir, 
por exemplo, aos ataques colonizadores do sistema, e sim, através da participação democrática, tentar reduzir a razão sistêmica à sua finalidade instrumental de reprodução material da sociedade, sem deixar que esta invada, de forma colonizadora, as instâncias simbólicas da sociedade, como é o caso da política, da ética e da educação, em que deveria prevalecer a lógica comunicativa.

A noção de ação social, referenciada pelos conceitos de sistema e mundo da vida, e o problema da "colonização", que emerge do desequilíbrio entre a reprodução material e simbólica da sociedade, suscitam em Habermas a necessidade de elaboração de uma teoria política conectada à teoria do direito, e com o foco no Estado Democrático de Direito. Nessa teoria, exposta em Faktizität und Geltung, de 1992, e traduzida para o português em 1997, sob o título Direito e Democracia, o autor desenvolve um paradigma procedimental do direito e da política, em que a ação política pressupõe o uso discursivo da razão prática.

Para Habermas (1992), o sistema político se diferencia internamente em domínios do poder administrativo e do poder comunicativo, sendo que a questão central da teoria política passa a ser então a de determinar a natureza das fronteiras entre esses domínios internos ao sistema político e das relações que se estabelecem entre eles. Dito de outra forma, como restaurar o equilíbrio entre o sistema e o mundo da vida, se a legitimidade da ação política requer um sistema administrativo eficaz e legitimado pelo fluxo comunicativo da esfera pública política?

Na tentativa de enfrentar esse problema, e de complementar a Teoria da Ação Comunicativa de 1981, Habermas (1992) entende que o direito possui a capacidade de desempenhar, numa via de mão dupla, a articulação entre o sistema e o mundo da vida. Isso pode ser constatado, de um lado, pelo fato de o direito desempenhar funções sistêmicas, representando a voz da administração e do sistema, e, do outro, pela capacidade de traduzir os influxos comunicativos do mundo da vida, sendo a expressão do processo de formação coletiva da opinião e vontade.

Na sociedade contemporânea, em que prevalece o Estado Democrático de Direito, Habermas observa que há uma complexa tensão entre "facticidade" e "validade", que pode tanto ser expressa internamente, no interior do próprio sistema de direitos, como externamente, na confrontação do direito com os contextos sociais. Essa tensão entre facticidade e validade é o que caracteriza, para Habermas (1992), uma teoria crítica do direito e da política, capaz de emancipar a sociedade. Ele entende ainda que a unidade entre as dimensões interna e externa da tensão entre facticidade e validade ocorre de forma procedimental e deliberativa, no sentido de articular o maior número possível de vozes, de tematizações, de valores e de interesses da sociedade civil. Essa 
é a forma insubstituível de tratar os conflitos que marcam profundamente a sociedade contemporânea, e a forma democrática de legitimação de um Estado Democrático de Direito.

O modelo democrático centrado na deliberação pública sempre ocupou um lugar de destaque nas formulações teóricas de Habermas. Em 1962, em seu trabalho intitulado Mudança Estrutural da Esfera Pública, o autor já ressaltava a importância da esfera pública, como base de legitimação da ação política. Esse espaço autônomo de deliberação pública, que se realiza fora do âmbito estatal, exerce uma força de integração social capaz de resistir às formas de dominação vigente. Cabe salientar que a formação de uma esfera pública hoje, tal como Habermas a vê, exige formas de entendimento e de convivência entre as pessoas, que desloca o sentido da legitimação social para as instâncias deliberativas da argumentação.

A leitura de Habermas sobre o fenômeno da globalização, descrita no ensaio A Constelação Pós-Nacional e o Futuro da Democracia, publicado na Alemanha em 1998, indica a necessidade de uma teoria política que seja capaz de transcender os limites estreitos dos Estados Nacionais. Assim, a democracia, que ainda se coloca no centro da teoria política contemporânea, necessita ser repensada a partir da ação efetiva das instituições democráticas e do papel dos cidadãos exercidos no contexto do espaço público e da sociedade civil. Não se trata de um modelo normativo de democracia, centrado no Estado, ou de um modelo representativo, que restringe a participação e o engajamento político à atuação de lideranças, mas de um modelo procedimental de democracia que considera como instância de legitimação a "razão" deliberada comunicativamente pela sociedade civil.

No modelo democrático de deliberação política, a participação dos cidadãos centra-se na formação racional da vontade política. Dessa forma, a legitimidade da ação política desloca-se do modelo inscrito na representação de uma "vontade geral" pré-determinada, para o modelo de "deliberação" oriundo do processo racional de formação da vontade dos cidadãos. Assim, as decisões políticas só se tornam legítimas quando são examinadas e aceitas racionalmente pelos cidadãos, e não porque representariam a "vontade" de uma suposta maioria.

Habermas (2003, p. 28-31) entende, à luz da teoria do discurso, e da Teoria do Agir Comunicativo, que o processo pleno de deliberação pública não pode ocorrer de forma distorcida, e, para tanto, é necessário que sejam considerados certos postulados: a) as deliberações precisam realizar-se de forma argumentativa, ou seja, mediante a troca regulada de informações e argumentos entre as partes, que recolhem e examinam criticamente propostas; $b$ ) as deliberações devem ser inclusivas e públicas, pois, em princípio, ninguém deve 
ser excluído, de modo que todos os possíveis interessados nas decisões têm iguais chances de aceso e de participação; c) os participantes devem ser soberanos, na medida em que estão submetidos apenas aos pressupostos da comunicação e às regras do procedimento argumentativo; d) as deliberações devem ser livres de coerções internas que possam colocar em risco a situação de igualdade dos participantes, uma vez que as tomadas de posição em termos de $\operatorname{sim} /$ não são movidas exclusivamente pela força não coativa do melhor argumento; e) as deliberações, em geral, devem visar um acordo motivado racionalmente, e podem, em princípio, ser desenvolvidas sem restrições ou retomadas a qualquer momento; f) as deliberações políticas devem abranger todas as matérias passíveis de regulação, tendo em vista o interesse simétrico de todos, não significando, porém, que certos temas e objetos, tradicionalmente tidos como de natureza "privada", não possam, em princípio, ser submetidos à discussão, dada a sua relevância pública; g) as deliberações políticas devem incluir também interpretações de necessidade e a transformação de preferências e enfoques pré-políticos.

Com base nos postulados apresentados acima, podemos dizer que, para Habermas (2003), o modelo procedimental de democracia consiste na autodeterminação pública de cidadãos que deliberam, a partir do processo racional de formação discursiva, a opinião e a vontade da sociedade civil. É dessa forma que o fluxo comunicativo da esfera pública informal converte-se, formalmente, em uma decisão política institucionalizada, com possibilidades reais de transformação do poder produzido comunicativamente em poder aplicável administrativamente, já que, segundo Habermas:

Os fluxos comunicacionais da esfera pública política estão especialmente expostos à pressão seletiva da inércia social; todavia a influência gerada por este caminho só pode transformar-se em poder político quando passar através das comportas do processo democrático e do sistema político em geral, instaurado na forma de Estado de direito (HABERMAS, 2003, p. 56).

A esfera pública (espaço público), que não pode ser concebida como uma instituição, nem como sistema ou organização, pois não há uma estrutura normativa de atuação, é o espaço da opinião pública que funciona como "uma rede adequada para a comunicação de conteúdos, tomadas de posição e opiniões, e nela os fluxos comunicacionais são filtrados e sintetizados, a ponto de se condensarem em opiniões públicas enfeixadas em termos específicos comunicacionais" (HABERMAS, 2003, p. 92). Trata-se, portanto, de um ambiente comunicativo orientado pelo entendimento e que reproduz o mundo da vida, na forma de uma grande "caixa de ressonância" das vontades e opiniões da sociedade civil. 
Habermas mostra claramente que a passagem de uma instância à outra não ocorre de forma mecânica, mas pelo médium do direito que detém a capacidade de articular, simultaneamente, tanto os aspectos administrativos do sistema, como os fluxos comunicativos do processo de formação coletiva da opinião e da vontade da sociedade civil.

Mesmo considerando a democracia como um elemento central da teoria política contemporânea, Habermas insiste na necessidade de uma ação mais efetiva das instituições democráticas e do papel dos cidadãos exercido no contexto do espaço público e da sociedade civil, já que, nas sociedades atuais, a integração social tem sido relegada a sistemas funcionais autônomos, dominados por subsistemas, em que prevalece o poder administrativo e estratégico.

Os subsistemas, fechados em si mesmos, representam uma forte ameaça às formas de socialização política da solidariedade social, pois acabam se distanciando dos reais problemas e interesses da maioria da população, gerando na sociedade uma atitude passiva, e com capacidade reduzida de pressão sobre as organizações sociais representativas. Trata-se, em última instância, de um processo de autonomização dos domínios da vida social, e que se institucionalizam, passando a ser orientados exclusivamente por critérios técnico-administrativos. Daí a importante função da sociedade civil, no sentido de "desenvolver impulsos vitais através de espaços públicos autônomos e capazes de ressonância, os quais podem introduzir no sistema político conflitos existentes na periferia" (HABERMAS, 2003, p. 58).

Dessa forma, o processo de "encapsulamento autopoiético" da política (LUHMANN, 1990), possibilitado pela "constelação pós-nacional", necessita ser pensado a partir de outro modelo de regulação política. Trata-se da política deliberativa, em que a formação de opinião e vontades democráticas apresenta-se como uma nova possibilidade de integração social, em substituição àquela representada pelo Estado Nacional. Agora, como resolver, em termos objetivos, esse grave problema da integração social da atualidade? Vejamos o encaminhamento de Habermas:

As questões de coordenação funcional, elaboradas politicamente, estão entrelaçadas com a dimensão ética e moral da integração social; isso decorre do fato de que, para percebermos as consequências de uma integração insuficiente do sistema, temos que recorrer ao pano de fundo do mundo da vida, ou seja, a interesses feridos ou a identidades ameaçadas. Por conseguinte, quando os processos de sintonia entre o Estado e os atores sociais tornam-se independentes em relação à esfera pública política e à formação da vontade parlamentar, resultam prejuízos, tanto do ponto de vista da legitimação, como do conhecimento. Sob ambos os pontos de vista, recomenda-se que a base 
ampliada do saber de uma administração reguladora assuma feições de uma política deliberativa, que se caracteriza pelo debate público entre especialistas e contra-especialistas, controlado pela opinião pública (HABERMAS, 2003, p. 83-84).

As palavras de Habermas são claras em relação ao potencial da política deliberativa, ou seja, das opiniões formadas pela sociedade civil no interior do espaço público, para o tratamento das questões que envolvem direta ou indiretamente a ação política. Isto significa que uma sociedade altamente complexa não pode se realizar, exclusivamente, através de um "sistema autoreferenciado" que ignora o poder comunicativo dos cidadãos.

De posse dos conceitos centrais do pensamento filosófico-político de Habermas, poderíamos agora indagar a respeito do lugar ocupado pela educação, nesse processo de formação política da sociedade contemporânea. Sobre essa questão, é importante considerar a análise empreendida por Pedro Goergen, no artigo Ação Comunicativa, Democracia e Educação:

A formação da vontade política se realiza em espaços e processos não necessariamente institucionalizados politicamente (...). Papel relevante cabe, nesse contexto, aos espaços da família, dos grupos de amigos, dos meios de comunicação e da educação formal. Em resumo, todos os contextos que constituem o espaço público no qual se articula a sociedade civil têm um papel essencial na formação e consolidação da vida política democrática (GOERGEN, 2008, p. 39).

A análise de Goergen, inspirada nas teses fundamentais de Habermas, procura mostrar que formação política perpassa tanto o sistema quanto os subsitemas organizados e institucionalizados com a finalidade de, representativamente, fazer frente aos problemas do conjunto da sociedade, no horizonte de expectativas emancipatórias. Dito de outra forma, para além dos interesses sistêmicos, há no contexto do espaço público a possibilidade de participação efetiva da sociedade civil, já que esta é a forma legítima de traduzir os reais interesses da sociedade.

Agora, a quem compete a formação política da sociedade civil? Às instâncias autorreferencialmente fechadas e reguladas pela lógica sistêmica do dinheiro e do poder? Há, ainda, outra instância de formação? A resposta de Habermas para essa questão indica que a educação, enquanto um subsistema, mantém um potencial crítico que deve ser considerado no processo formativo. Trata-se do potencial comunicativo inscrito na linguagem ordinária que, por seu caráter multifuncional e de não especialização, se oferece como meio de ação orientada ao entendimento pelo qual se reproduzem e se entrelaçam 
os componentes do mundo da vida. Isso significa que o processo formativo deve contar com a força da opinião pública gerada nos espaços comunicativos e não burocratizados do mundo da vida. Retomando a análise de Goergen:

Se considerarmos os âmbitos da educação e da ciência como partes integrantes do mundo comunicativo e não subservientes ao sistema, podemos dizer que, antes de tudo, sua contribuição para a legitimidade de um sistema democrático pode consistir, inicialmente, na formação de uma nova consciência social e no despertar da sensibilidade política dos cidadãos e, posteriormente, na formação intelectual dos cidadãos, de modo que além de conscientes, estes também saibam formular e defender, com bons argumentos, os reais interesses da sociedade civil (GOERGEN, 2008, p. 64).

Nessa perspectiva de análise, que prevê a formação da sensibilidade política, Habermas acredita que o Estado Democrático, representado pelas instâncias institucionais do Poder Público, possui elementos de articulação que podem suscitar a participação efetiva da sociedade. Daí a importância do fortalecimento da esfera pública, enquanto espaço legítimo de articulação política da sociedade civil.

Para tanto, é fundamental que a sociedade esteja em permanente processo de formação, e que haja sempre uma preocupação com o desenvolvimento da consciência política dos cidadãos, a fim de garantir a discussão pública dos temas que afetam os reais interesses da sociedade civil.

Sabemos, no entanto, que a perspectiva de uma política deliberativa, na forma como Habermas a entende, não está livre de certos limites, seja pelas condições materiais ou formativas das diferentes sociedades, seja pela não observância, por parte dos atores sociais, dos postulados que condicionam a efetiva participação democrática dos cidadãos. A esse respeito, o estudo intitulado O Desafio da Construção de um Modelo Democrático Deliberativo, desenvolvido por Gabriel Vitullo em 2000, pode ser um bom ponto de partida para a análise crítica dos limites entre o ideal deliberativo e a realidade das sociedades contemporâneas, circunscrito numa proposta como essa.

Entre os temas ou questões que poderiam ser objeto de análise, quanto à viabilidade real da proposta político-deliberativa de Habermas, destacam-se: a possibilidade de participação de toda a sociedade nos processos de decisão; a igualdade de oportunidades para tomar parte na deliberação; o intercâmbio livre e aberto de informações e razões, em medida suficiente para alcançar o conhecimento mínimo dos assuntos em discussão; os recursos simbólicos necessários para a participação em uma discussão pública; em resumo, como pensar em um diálogo igualitário quando os participantes estão em situação desigual de nível intelectual, econômico e moral? 


\section{Considerações finais}

A Teoria Crítica da Sociedade, na forma como foi apresentada aqui, continua fornecendo os elementos necessários para realização da crítica social contemporânea. A orientação para a emancipação, que fundamenta o pensamento da tradição intelectual da Escola de Frankfurt, é um exemplo claro de que ainda há espaço para as reflexões dessa natureza. Acreditamos, ainda, que a Teoria Crítica continua sendo extremamente fecunda para as reflexões no campo educacional, especialmente na análise dos limites e possibilidades de um projeto emancipatório de formação social. Foi com esse referencial teórico que procuramos desenvolver uma reflexão específica sobre a importância do resgate do sentido político da educação. Tal preocupação parece estar, no entanto, bem distante dos projetos educacionais atuais, o que nos coloca em estado de vigilância crítica sobre os conteúdos e processos que determinam a formação da sociedade atual.

Como vimos, a partir do pensamento teórico-crítico de Adorno, numa sociedade em que prevalece a racionalidade técnico-instrumental e o poder ideológico da indústria cultural, a dimensão crítica da cultura, que deveria garantir a emancipação, se desvincula da ação social e acaba cedendo lugar a Halbbildung, que passa a ser a forma dominante da consciência social voltada para a adaptação e o conformismo. Daí a necessidade, em termos emancipatórios, de uma educação que privilegie a auto-reflexão crítica sobre o processo de semiformação da sociedade, em que ela necessariamente se converteu. A determinação política da educação decorre exatamente da necessidade de formação de sujeitos emancipados, livres da condição de alienação e enclausuramento social.

Com Habermas, foi possível demonstrar que a sobreposição do poder administrativo sobre o poder comunicativo acaba gerando um profundo estado de debilidade social. O esvaziamento da esfera pública e o distanciamento da sociedade civil dos debates relacionados à vida política são os sintomas de uma sociedade ameaçada pelos interesses sistêmicos do dinheiro e do poder. Como não se trata de um processo natural, mas ideológico, a sociedade pode reverter essa condição, mediante o restabelecimento do vínculo entre a esfera pública e a sociedade civil. A educação pode ajudar a desenvolver a consciência política dos cidadãos, com o fortalecimento da capacidade avaliativa e argumentativa das pessoas, viabilizando, dessa forma, o debate público de discussão e de deliberação dos interesses da sociedade civil, para o exercício democrático efetivo de uma sociedade de direitos.

Sabemos, no entanto, que essa não é uma tarefa fácil, principalmente porque os espaços de circulação do pensamento livre e criativo ainda são muito 
limitados. Concordando com a análise de Vitullo (2000), para que a discussão pública incorpore as múltiplas e diferentes perspectivas, as condições materiais e sociais que o façam possível precisam ser viabilizadas. Independentemente do foco formativo, o sujeito, no caso de Adorno, ou a esfera pública no caso de Habermas, não há dúvidas de que a educação ocupa um lugar importante nesse processo de formação política, a ponto de definir os princípios que nortearão as bases de uma determinada sociedade. Resta saber se os sujeitos que formam a orientação democrática, em pleno processo de construção coletiva, terão forças suficientes para fortalecer o espaço público e criar uma condição de vida mais humana e favorável ao nosso planeta.

Essas reflexões não tiveram outro objetivo senão o de tentar retomar o debate sobre a dimensão política da educação, que no passado recente ocupou o centro de várias teorias educacionais no Brasil e na América Latina, especialmente aquelas que traduziam uma das principais teses de Paulo Freire (1980), de que a "educação é um ato político". Não se trata de um discurso nostálgico, mas de resistência à forma como o "privado" tem suplantado as instâncias de formação cultural do "bem comum".

\section{Referências}

ADORNO, Theodor Wiesengrund. Prismas: crítica cultural e sociedade. Trad.: Augustin Wernet e Jorge Mattos Brito de Almeida. São Paulo: Ática, 1998.

Teoria da semicultura. Trad.: Newton Ramos de Oliveira, Bruno Pucci e Cláudia B. M. de Abreu. Educação e Sociedade, Campinas: Papirus, v. 17, n. 56, p. 388-411, dez. 1996.

. Educação e emancipação. Trad.: Wolfgang Leo Maar. Rio de Janeiro: Paz e Terra, 1995a.

Tempo Livre. In: ADORNO, Theodor W. Palavras e sinais: modelos críticos

2. Trad.: Maria Helena Ruschel. Petrópolis: Vozes, p. 70-82, $1995 \mathrm{~b}$.

. Dialética negativa. Trad.: José Maria Ripalda. Madrid: Taurus, 1975.

ADORNO, Theodor W.; HORKHEIMER, Max. Dialética do esclarecimento: fragmentos filosóficos. Trad.: Guido Antonio de Almeida. Rio de Janeiro: J. Zahar, 1985.

BAUMAN, Zygmunt. Em busca da política. Trad.: Marcus Penchel. Rio de Janeiro: J. Zahar, 2000.

CULLEN, Carlos. Perfiles ético-políticos de la educación. Buenos Aires: Paidós, 2008.

FREIRE, Paulo. A pedagogia do oprimido. Rio de Janeiro: Paz e Terra, 1980.

FUKUYAMA, Francis; MIKE, Davis; ALENCASTRO, Luiz Felipe de. O mundo pósglobal. Folha de São Paulo - Caderno Mais. São Paulo, n. 880, 15 fev. 2009. 
GOERGEN, Pedro. Ação comunicativa, democracia e educação. In: SGRÓ, Margarita R. Teoría crítica de la sociedad, educación, democracia y ciudadanía. Tandil: Editora da Univ. Nacional Del Centro de la Província de Buenos Aires, 2008. p. 33-72.

HABERMAS, Jürgen. Direito e democracia: entre facticidade e validade II. Trad.: Flávio Beno Siebeneichler. Rio de Janeiro: Tempo Brasileiro, 2003.

- A constelação pós-nacional: ensaios políticos. Trad.: Márcio Seligmann-Silva. São Paulo: Littera Mundi, 2001.

. O discurso filosófico da modernidade. Trad.: Luiz Sérgio Repa e Rodnei Nascimento. São Paulo: Martins Fontes, 2000.

. Teoría de la acción comunicativa I: racionalidad de la acción y racionalización social. Madrid: Taurus, 1999a.

- Teoría de la acción comunicativa II: crítica de la razón funcionalista. Madrid: Taurus, 1999b.

. Faktizität und geltung. Frankfurt am Main: Suhrkamp Verlag, 1992.

. Mudança estrutural da esfera pública: investigações quanto a uma categoria da sociedade burguesa. Trad.: Flavio Kothe. Rio de Janeiro: Tempo Brasileiro, 1984.

IANNI, Octavio. A sociedade global. Rio de Janeiro: Civilização Brasileira, 2002.

KANT, Immanuel. Resposta à pergunta: que é esclarecimento? In: Textos seletos (edição bilíngue). Trad.: Francisco de Sousa Fernandes. Petrópolis: Vozes, 1985. p. 101-117.

LUHMANN, Niklas. The autopoiesis of social systems. In: . Essays on selfreference. New York: Columbia University Press, 1990, p. 1-21.

LYOTARD, Jean-François. A condição pós-moderna. Trad.: Ricardo Corrêa Barbosa. Rio de Janeiro: José Olympio, 2002.

MAAR, Wofgang Leo. À guisa de introdução: Adorno e a experiência formativa. In: ADORNO, Theodor W. Educação e emancipação. Rio de Janeiro: Paz e Terra, 1995. SANTOS, Boaventura de Sousa. A globalização e as ciências sociais. São Paulo: Cortez, 2005.

VATTIMO, Gianni. O fim da modernidade: niilismo e hermenêutica na cultura pósmoderna. Trad.: Eduardo Brandão. São Paulo: Martins Fontes, 2002.

VITULLO, Gabriel E. O desafio da construção de um modelo democrático deliberativo. Sociologias: Revista do Programa de Pós-Graduação em Sociologia da UFRGS. Porto Alegre, v. 2, n. 3, p. 186-231, jan./ jun. 2000.

WEBER, Max. A ética protestante e o espírito do capitalismo. Trad.: José Marcos Mariani de Macedo. São Paulo: Companhia das Letras, 2007. 


\section{Critical Theory of Society and the political direction of education Abstract}

The article points out, within the intellectual tradition of the Critical Theory of Society, the political direction of education. The question is to enhance the project of social emancipation and the possibilities of carrying out a non conformist experience of existing reality. In this context, two theoretical perspectives of the frankfurtian meaning of Critical Theory will be presented. They consider as a condition for the formation of emancipated persons the link between education and politics: that of Theodor Adorno, in which true education transcends the dimension of adaptation to the real world, through the repositioning of the formative experience (Bildung), as a form of criticism to the semiformation condition (Halbbildung); and that of Jürgen Habermas, in which education must form the evaluative and argumentative capacity of citizens, in order to fortify the public space, and to guarantee the effective participation of the interests of civil society.

Keywords: Critical Theory. Politics. Education.

\section{La théorie critique de la société et le sens politique de l'éducation Résumé}

L'article situe dans la tradition de la Théorie Critique de la Société le sens public de l'éducation. Il s'agit de mettre en évidence le projet d'émancipation sociale et les possibilités de réalisation d'une expérience non-conformiste en relation à la réalité existante. Dans ce contexte, nous présenterons deux perspectives théoriques de l'acceptation frankfurtienne de la théorie critique qui considèrent comme condition pour la formation des personnes émancipées la relation entre éducation et politique : celle de Theodor Adorno, dans laquelle la vraie éducation transcende la dimension de l'adaptation au monde existant au travers du repositionnement de l'expérience formative (Bildung), comme forme de critique à la condition de semiformation (Halbbildung); et celle de Jürgen Habermas, dans laquelle l'éducation doit former la capacité évaluative et argumentative des citoyens, afin de fortifier l'espace public et garantir la participation effective des intérêts de la société civile.

Mots clefs : Théorie Critique. Politique. Éducation. 


\section{Teoría Crítica de la Sociedad y el sentido político de la educación Resumen}

El artículo sitúa, en la tradición intelectual de la Teoría Crítica de la Sociedad, el sentido político de la educación. Se trata de poner en evidencia el proyecto de emancipación social y las posibilidades de realización de una experiencia no conformista de la realidad existente. En ese contexto, serán presentadas dos perspectivas teóricas de la acepción frankfurtiana de la teoría crítica, y que consideran como condición para la formación de personas emancipadas, la vinculación entre educación y política: la de Theodor Adorno, en que la educación verdadera transcende la dimensión de la adaptación al mundo vigente, a través de la recolocación de la experiencia formativa (Bildung) como forma de crítica a la condición de semiformación (Halbbildung); y la de Jürgen Habermas, en que la educación debe formar la capacidad evaluativa y argumentativa de los ciudadanos, a fin de fortalecer el espacio público, y garantizar la participación efectiva de los intereses de la sociedad civil.

Palabras clave: Teoría crítica. Política. Educación.

Recebido em: 10.08 .2010

Aceito em: 17.09.2010 